\title{
Review \\ Clinical review: Major consequences of illicit drug consumption
} Robert J Devlin ${ }^{1}$ and John A Henry²

\author{
'Guy's and St Thomas' NHS Foundation Trust, Lambeth Palace Road, London SE1 7EH, UK \\ 2Department of Emergency Medicine, St Mary's Hospital, South Wharf Road, London W2 1NY, UK
}

Corresponding author: John A Henry, j.a.henry@imperial.ac.uk

Published: 11 January 2008

This article is online at http://ccforum.com/content/12/1/202

(c) 2008 BioMed Central Ltd

\begin{abstract}
Because illicit drugs are now widely consumed, every doctor needs to know their acute medical consequences and complications. Here, we review the problems associated with the different drugs from a systems-based viewpoint. Apart from the respiratory depressant effect of opioids, crack cocaine is the most common cause of respiratory complications, mainly linked with its mode of use, with airway burns, pneumothorax, pneumomediastinum, and lung syndromes being well-recognised sequelae. Because of its marked cardiovascular effects, cocaine is also a major cause of coronary syndromes and myocardial infarction. Amphetamines may produce similar effects less commonly. Hyperthermia may occur with cocaine toxicity or with 3,4-methylenedioxymethamphetamine (MDMA) due to exertion or from serotonin syndrome. Cerebral haemorrhage may result from the use of amphetamines or cocaine. Hallucinations may follow consumption of LSD, amphetamines, or cocaine. MDMA is a major cause of acute severe hyponatraemia and also has been linked with hepatic syndromes. Collapse, convulsions, or coma may be caused in different circumstances by opioids, MDMA, or gamma hydroxybutyrate and may be aggravated by other sedatives, especially alcohol and benzodiazepines. Recognition of these acute complications is urgent, and treatment must be based on an understanding of the likely underlying problem as well as on basic principles of supportive care.
\end{abstract}

\section{Introduction}

Many substances are now widely taken for their mind-altering properties. Their sought-after effects may be outweighed in many cases by the dependence produced and, in a small number of cases, by the medical complications that they may cause. These complications do not often present a critical threat to health, but when they do, the clinical diagnosis is important and management often needs to be urgent and decisive. The emergency may present outside the hospital, in the emergency department, or in the intensive therapy unit, and the diagnostic and therapeutic approach to the clinical problem must be appropriate to each situation. Because the general properties of the different substances are well known and because polysubstance misuse is now very common, we are adopting a systems-oriented approach to the main acute complications of the currently available illicit substances (see Table 1 for summary).

\section{Respiratory complications}

The illicit substance most commonly associated with respiratory complications requiring hospital admission is crack cocaine. Smoking of crack cocaine (which vaporises at $187^{\circ} \mathrm{C}$ ) can lead to thermal injury of the pharynx and airways, which may be severe [1]. However, cough, haemoptysis, pneumothorax, pneumomediastinum, pneumopericardium, and haemothorax are the main acute complications of inhaling crack cocaine vapour. Users commonly inhale deeply and then perform a Valsalva manoeuvre to accentuate the absorption and effects of the drug. It is likely that this rise in intraalveolar pressure in addition to barotrauma caused by vigorous coughing causes alveolar rupture and the dissection of air in the peribronchiolar connective tissue. Similar complications are seen less commonly in cannabis smokers who also inhale deeply and retain the smoke to facilitate absorption of tetrahydrocannabinol, or THC. Both cocaine [2] and cannabis [3] smoking as well as intravenous methylphenidate abuse [4] have been associated with severe bullous emphysema, one complication of which is pneumothorax. Management of these complications follows conventional lines.

The principal subacute pulmonary complications of cocaine use include pulmonary oedema, 'crack lung', interstitial pneumonitis, and bronchiolitis obliterans with organising pneumonia (BOOP). The diagnosis of cocaine-associated pulmonary oedema may be delayed as clinicians may be misled by the young age of the patient. Treatment with diuretics, nitrates, and oxygen followed by mechanical ventilation, if necessary, usually produces rapid improvement. The pathogenesis of this condition is unclear, but the negative inotropic effect of cocaine, which is often marked at high doses, may be an important factor [5]. Crack lung is the

$\mathrm{ADH}=$ antidiuretic hormone; $\mathrm{BOOP}=$ bronchiolitis obliterans with organising pneumonia; $\mathrm{CK}=$ creatine kinase; $\mathrm{ECG}=$ electrocardiogram; $\mathrm{GHB}=$ gamma hydroxybutyrate; GTN = glyceryl trinitrate; MDMA = 3,4-methylenedioxymethamphetamine; $\mathrm{Ml}=$ myocardial infarction. 
Critical Care Vol 12 No 1 Devlin and Henry

Table 1

Summary of major complications following illicit drug use

\begin{tabular}{|c|c|c|c|c|}
\hline Presentation & & Substances implicated & Mechanism & Specific treatment \\
\hline \multirow[t]{4}{*}{ Respiratory compromise } & $\begin{array}{l}\text { Pneumothorax, } \\
\text { haemothorax }\end{array}$ & Cocaine, cannabis & Barotrauma & Chest drainage \\
\hline & 'Crack lung' & Cocaine & $\begin{array}{l}\text { Interstitial and alveolar } \\
\text { inflammatory infiltration }\end{array}$ & $\begin{array}{l}\text { Systemic corticosteroid } \\
\text { administration }\end{array}$ \\
\hline & Pulmonary oedema & Cocaine & & Oxygen, diuretics, nitrates \\
\hline & $\begin{array}{l}\text { Interstitial pneumonitis, } \\
\text { BOOP }\end{array}$ & Cocaine & & $\begin{array}{l}\text { Ventilation where } \\
\text { necessary }\end{array}$ \\
\hline \multirow[t]{5}{*}{ Chest pain/cardiovascular collapse } & $\begin{array}{l}\text { Pneumomediastinum, } \\
\text { pneumopericardium }\end{array}$ & Cocaine, cannabis & Barotrauma & $\begin{array}{l}\text { Drainage where } \\
\text { necessary }\end{array}$ \\
\hline & $\begin{array}{l}\text { Acute coronary } \\
\text { syndrome }\end{array}$ & Cocaine & $\begin{array}{l}\text { Alpha-adrenergic } \\
\text { vasoconstriction, } \\
\text { platelet aggregation }\end{array}$ & $\begin{array}{l}\text { Sublingual nitrates, } \\
\text { benzodiazepines }\end{array}$ \\
\hline & $\begin{array}{l}\text { Arrhythmias and } \\
\text { sudden death }\end{array}$ & Cocaine & $\begin{array}{l}\text { Sodium channel } \\
\text { blockade }\end{array}$ & \\
\hline & & Amphetamines & $\begin{array}{l}\text { Sympathetic } \\
\text { hyperstimulation }\end{array}$ & \\
\hline & & Cannabis & & \\
\hline \multirow[t]{4}{*}{$\begin{array}{l}\text { Confusion, convulsions, } \\
\text { collapse, coma }\end{array}$} & $\begin{array}{l}\text { With respiratory } \\
\text { depression }\end{array}$ & $\begin{array}{l}\text { Opioids, benzodiazepines, } \\
\text { ethanol, GHB }\end{array}$ & Central sedation & $\begin{array}{l}\text { Airway protection, } \\
\text { ventilation }\end{array}$ \\
\hline & With hyponaturaemia & MDMA & $\begin{array}{l}\text { Cerebral oedema } \\
\text { (excess fluid consumption } \\
\text { and } A D H \text { release) }\end{array}$ & $\begin{array}{l}\text { Fluid restriction, } \\
\text { hypertonic saline } \\
\text { administration }\end{array}$ \\
\hline & $\begin{array}{l}\text { Predominantly seizure } \\
\text { activity }\end{array}$ & $\begin{array}{l}\text { Cocaine, } \\
\text { amphetamines }\end{array}$ & $\begin{array}{l}\text { Central nervous system } \\
\text { stimulation }\end{array}$ & Benzodiazepines \\
\hline & & $\begin{array}{l}\text { Opioids, GHB, } \\
\text { benzodiazepines, ethanol }\end{array}$ & Withdrawal & \\
\hline \multirow[t]{3}{*}{ Hyperthermia } & $\begin{array}{l}\text { With agitated and } \\
\text { paranoid behaviour, } \\
\text { collapse, and death }\end{array}$ & $\begin{array}{l}\text { Cocaine (excited } \\
\text { delirium) }\end{array}$ & & $\begin{array}{l}\text { Benzodiazepines, fluid } \\
\text { resuscitation }\end{array}$ \\
\hline & $\begin{array}{l}\text { In extremis without } \\
\text { rigidity }\end{array}$ & $\begin{array}{l}\text { MDMA (exertional } \\
\text { hyperpyrexia) }\end{array}$ & $\begin{array}{l}\text { Exertion, dehydration, } \\
\text { arousal, environmental } \\
\text { warming, alterations } \\
\text { in skeletal muscle } \\
\text { excitation-contraction } \\
\text { coupling }\end{array}$ & $\begin{array}{l}\text { Active cooling } \pm \\
\text { dantrolene }\end{array}$ \\
\hline & With rigidity & $\begin{array}{l}\text { MDMA (serotonin } \\
\text { syndrome) }\end{array}$ & $\begin{array}{l}\text { Contraction of } \\
\text { antagonistic muscle } \\
\text { groups }\end{array}$ & Paralysis \\
\hline \multirow[t]{3}{*}{ Rhabdomyolysis } & With coma & $\begin{array}{l}\text { Opioids, benzodiazepines, } \\
\text { ethanol, GHB }\end{array}$ & Pressure necrosis & $\begin{array}{l}\text { Fluid administration, } \\
\text { monitor for acute renal } \\
\text { failure }\end{array}$ \\
\hline & $\begin{array}{l}\text { With excessive muscle } \\
\text { contraction }\end{array}$ & MDMA & Diffuse tissue disruption & \\
\hline & Traumatic & Any & $\begin{array}{l}\text { Impaired judgement, } \\
\text { risk-taking behaviours }\end{array}$ & \\
\hline
\end{tabular}

$\mathrm{ADH}$, antidiuretic hormone; BOOP, bronchiolitis obliterans with organising pneumonia; GHB, gamma hydroxybutyrate; MDMA, 3,4methylenedioxymethamphetamine. 
term given to acute dyspnoea and hypoxaemia, together with (in more severe cases) fever, haemoptysis, and respiratory failure in crack cocaine users [6]. Lung biopsy reveals diffuse alveolar damage, alveolar haemorrhage, and interstitial and intra-alveolar inflammatory cell infiltration which is eosinophilic in severe cases. These improve promptly with systemic corticosteroid administration, whereas milder cases usually resolve spontaneously within 36 hours. In rare cases, crack users may develop adult respiratory distress syndrome and end-stage respiratory failure due to crack-associated interstitial pneumonitis and BOOP. Use of cocaine or heroin by inhalation can also lead to severe asthma [7].

Respiratory depression with bradypnoea and hypoxaemia caused by diamorphine overdose is well known and readily recognised by most clinicians. Similarly, the management is straightforward, first ensuring a patent airway and administering oxygen followed by naloxone or continued respiratory support. It is important to remember that the half-life of naloxone is shorter than that of most commonly abused opioids and thus readministration may be necessary. Respiratory depression and hypostatic pneumonia may occur in gamma hydroxybutyrate (GHB) intoxication. There is no effective antidote, so these patients may require intubation and mechanical ventilation. However, rapid recovery is common, and the patient may improve as preparations for further care are being made.

\section{Cardiovascular complications}

Cocaine is the most common cause of chest pain in young adults presenting to emergency departments and, in the United States, is the cause of $25 \%$ of myocardial infarctions (Mls) in people under 45 years of age [8]. The alphaadrenergic effect produced by the blockade of norepinephrine reuptake causes coronary vasoconstriction, as has been demonstrated with coronary angiography $[9,10]$. Additionally, cocaine promotes platelet aggregation and in situ thrombus formation and, in the longer term, accelerates atherosclerosis and produces left ventricular hypertrophy [11]. Widespread vasoconstriction causes increased myocardial oxygen demand, and with cocaine's sympathomimetic activity causing tachycardia and hypertension, myocardial ischaemia and infarction may occur; the risk of $\mathrm{Ml}$ in patients with cocaineinduced chest pain is approximately $6 \%$. The usual clinical presentation is of an acute coronary syndrome in a young individual often without risk factors for ischaemic heart disease. Electrocardiogram (ECG) interpretation in these instances is extremely difficult and often ineffective in excluding or confirming MI. Forty-three percent of cocaineusing patients without infarction meet ECG criteria for thrombolysis. Cardiac troponins are much more reliable in this respect [12]. Consequently, most patients with clinical findings suggestive of cocaine-associated chest pain are admitted to the hospital. Creatine kinase (CK) and myocardial CK may well be elevated in the absence of Ml, due to increased motor activity, hyperthermia, and skeletal-muscle injury.
Management is with oxygen, aspirin (unless at risk of subarachnoid haemorrhage), benzodiazepines, and sublingual nitrates. The benefit of coadministration of sublingual nitrates and benzodiazepines has been a topic of recent investigation. Baumann and colleagues [13] were unable to find evidence of benefit in the coadministration of glyceryl trinitrate (GTN) with diazepam over monotherapy in terms of chest pain resolution and cardiac performance, perhaps due to a lack of statistical power. Honderick and colleagues [14] demonstrated an advantage in dual therapy (GTN and lorazepam) over monotherapy (GTN), although the lack of a placebo control and the failure to analyse by intention to treat reduce the clinical applicability of these findings. Moreover, the clinical reality is that these patients are prone to seizures due to their cocaine usage, which provides a compelling rationale for the urgent prophylactic use of benzodiazepines in these situations. Most clinicians would agree that benzodiazepines should be given to all patients with cocaine-induced chest pain who are anxious, tachycardic, or hypertensive.

In contrast, a clear consensus exists against the use of betablockers, which have been shown to potentiate cocaineinduced chest pain via unopposed alpha-adrenergic stimulation $[15,16]$. Given the difficulty in definitively diagnosing cocaine-induced $\mathrm{Ml}$, thrombolysis is rarely resorted to. The infarction is often due to coronary spasm rather than thrombosis, with evident implications for management; the mortality for cocaine-induced $\mathrm{Ml}$ is extremely low in patients who reach the hospital alive.

Cocaine has also been associated with hypotension, cardiac arrhythmias, and sudden death due to sodium channel blockade if taken in large quantities. Other substances associated with cardiac arrhythmias and sudden death include 3,4-methylenedioxymethamphetamine (MDMA or 'ecstasy'), amphetamines, and cannabis, thought to be linked to sympathetic hyperstimulation in the case of MDMA and amphetamines. In many young victims of sudden death, it is possible that death may be due to undiagnosed conduction defects precipitated by illicit substance consumption. MDMA, however, has a clear association with QT prolongation. Methadone, often sold on the illicit market, is an important cause of long QT syndrome and torsades de pointes [17].

\section{Neurological complications}

Deep coma may result from the consumption of illicit drugs, particularly opioids or $\mathrm{GHB}$, often in combination with alcohol or benzodiazepines. GHB is a GABA analogue (as are its precursors, gamma butyrolactone and 1,4-butanediol) whose peak effects occur at approximately 30 to 45 minutes after oral consumption and last for up to approximately 2.5 hours. Volatile substance abuse may also result in coma. Respiratory depression, aspiration of vomit, positional asphyxia, nontraumatic rhabdomyolysis, and other complications may follow depending on the depth and duration of central nervous system depression. Management is supportive; naloxone may 
be used if opioid toxicity is apparent or suspected. Because of the risk of provoking convulsions, flumazenil is not recommended for reversal of benzodiazepine toxicity, and physostigmine does not have a recommended role in reversing GHB toxicity. Although ketamine is an anaesthetic agent, toxicity rarely causes coma. More likely are euphoria, numbness, 'out of body' sensations, confusion, disorientation, and panic attacks.

Seizures may be caused by cocaine, amphetamines (including MDMA), withdrawal states (opioids, GHB, benzodiazepines, and ethanol), and cerebral hypoxia. Though often short-lived, they need to be controlled by benzodiazepines in the first instance. Hallucinations can follow consumption of LSD, psilocybe mushrooms, amphetamines, or cocaine. With cocaine, hallucinations may be a relatively isolated unwanted effect or may be part of cocaine-excited delirium. They also occur in withdrawal states, most notably that of alcohol, but also of benzodiazepines, GHB, and opioids.

A number of deaths from acute hyponatraemia have been reported in association with MDMA abuse. The basic mechanism is straightforward: MDMA causes excess antidiuretic hormone $(\mathrm{ADH})$ production and thus a reduced renal response to water loading, so that excess fluid ingestion following MDMA leads to dilutional hyponatraemia and cerebral oedema [18]. The most common presentation is neurological, with confusion, delirium, convulsions, or coma. More severe cerebral oedema may cause cerebral hypoxia and uncal herniation. Pulmonary oedema may also occur. The most important aspect of management is fluid restriction. Most patients will produce a diuresis within hours as levels of MDMA fall and ADH production resumes. However, in a minority of severely ill patients, hypertonic saline may be required. It should be noted that the chances of osmotic demyelination syndrome on sodium repletion are extremely remote in MDMA-associated hyponatraemia because the derangement is acute in nature.

Stimulant drugs such as cocaine and amphetamines have been associated with cerebrovascular events $[19,20]$. Both have now been demonstrated in epidemiological studies; the likelihood of haemorrhagic stroke is more common with amphetamines, whereas thrombotic stroke is more common with cocaine. Subarachnoid haemorrhage is likely to be more severe and to have a worse outcome when cocaine is implicated [21]. Spongiform leukoencephalopathy is an unusual complication of illicit drug misuse with severe, often fatal, neurological deterioration and lesions of the white matter of the cerebrum, cerebellum, and basal ganglia, most often precipitated by inhalation of vaporised heroin [22].

\section{Hyperthermic complications}

Excessive cocaine use can result in hallucinations, agitation, and hyperthermia, and management is urgent. In addition, cocaine-excited delirium, an important but unusual complica- tion of cocaine use and considered to be an entity separate from cocaine toxicity, is characterised by hyperthermia with profuse sweating, followed by agitated and paranoid behaviour (with dilated pupils); these extreme behavioural disturbances may progress to collapse (often accompanied by respiratory arrest) and death (cardiorespiratory arrest). It occurs in regular cocaine users who have used the drug in the previous 24 hours. Risk factors identified for fatal cocaine-excited delirium include Afro-Caribbean race, male gender, and administration of cocaine by smoking or injection [23]. Warm summer weather also appears to be a precipitant [24]. Despite the serious clinical problem and the risk of death in police custody prior to admission, there are no clear guidelines on the management of this condition, perhaps due to its infrequent occurrence. Diazepam or lorazepam is known to be effective in reducing neuronal excitation and its consequences and in acting as a chemical restraint in the interests of public safety. Urgent fluid resuscitation is also likely to be of importance given the presence of hyperpyrexia. The place of dopamine antagonists has not been established.

The hyperthermic complications of MDMA use are well known. They can broadly be divided into two syndromes, exertional hyperpyrexia and serotonin syndrome, although the two may overlap. In exertional hyperpyrexia, it is clear that the circumstances in which the drug is taken are important in the development of this complication as implied by its frequent occurrence in club-goers following prolonged dancing $[25,26]$. This hypothesis is supported by animal studies demonstrating increased hyperthermic response to MDMA in warm crowded environments [27]. Patients may present in extremis, collapsed, hypotensive, and tachycardic, with hyperpyrexia without rigidity. Rhabdomyolysis may or may not be present. Rapid deterioration may ensue, with impairment of consciousness, disseminated intravascular coagulation, and multi-organ failure (frequently five-organ failure). When present, rhabdomyolysis is often marked, with peak serum CK levels of 30,000 to $100,000 \mathrm{U} / \mathrm{L}$. Prognosis correlates with peak core temperature, with few survivors presenting with temperatures in excess of $42^{\circ} \mathrm{C}$ (the highest temperature recorded in a survivor was $42.9^{\circ} \mathrm{C}$ ) [28]. Given the potentially fatal nature of this condition, it is essential that the diagnosis be made rapidly and appropriate management instituted immediately. This consists essentially in fluid replacement to support cardiac output and facilitate thermoregulation, rapid cooling, and support for failing organ systems, often including intubation, ventilation, and invasive monitoring.

The effect of hyperthermia on skeletal muscle is to reduce the calcium requirement for excitation-contraction coupling and thus establish a vicious cycle of heat production secondary to muscle contraction. This is the rationale behind using dantrolene to aid cooling of these patients, although its benefit is uncertain. There has been no comparative study of dantrolene in acute drug-induced hyperthermia, although it has been studied in environmental heatstroke. In a 
Table 2

\begin{tabular}{|c|c|c|}
\hline Toxidrome & Features & Drugs implicated \\
\hline Adrenergic & $\begin{array}{l}\text { Hypertension, tachycardia, mydriasis, diaphoresis, agitation, } \\
\text { dry mucus membranes }\end{array}$ & Amphetamines, cocaine, ephedrine, phencyclidine \\
\hline Sedative & Stupor and coma, confusion, slurred speech, apnea & Barbiturates, benzodiazepines, ethanol, opiates \\
\hline Hallucinogenic & Hallucinations, psychosis, panic, fever, hyperthermia & Amphetamines, cannabinoids, cocaine \\
\hline Narcotic & $\begin{array}{l}\text { Altered mental status, slow shallow breaths, miosis, bradycardia, } \\
\text { hypotension, hypothermia, decreased bowel sounds }\end{array}$ & Opiates \\
\hline Epileptogenic & Hyperthermia, hyperrreflexia, tremors, seizures & Cocaine, phencyclidine \\
\hline
\end{tabular}

Adapted from [35].

randomised double-blind controlled trial conducted in 52 patients, dantrolene did not affect the rate of cooling [29]. A recent review of case reports divided cases into groups based on peak temperature. What emerged was that, in patients whose peak temperature was $40.0^{\circ} \mathrm{C}$ to $41.9^{\circ} \mathrm{C}$, there were $10 / 10$ survivors in the dantrolene-treated group and 6/10 survivors in the non-dantrolene-treated group [30]. Patients with temperatures above $42^{\circ} \mathrm{C}$ tended to die irrespective of treatment, whereas those with peak temperatures below $40^{\circ} \mathrm{C}$ rarely developed rhabdomyolysis and multiorgan failure. These figures clearly must be interpreted with considerable caution, not least because of possible publication bias. However, it may be that the benefits of dantrolene are restricted to patients with high peak temperatures (in the $40^{\circ} \mathrm{C}$ to $42^{\circ} \mathrm{C}$ range), whereas less importance may need to be placed on reports of the efficacy of dantrolene in patients with lower peak temperatures.

Serotonin syndrome, in contrast, is characterised by rapid onset of markedly increased muscle tone amounting to myoclonus, with shivering, tremor, and hyperreflexia. Contraction of opposed muscle groups tends to generate heat at a greater rate than can be lost by vasodilatation and sweating, leading to hyperpyrexia and cardiovascular instability. In addition, the patient may have confusion and diarrhoea. Mortality is reported as $10 \%$ to $15 \%$ [30]. Patients on monoamine oxidase inhibitors and selective serotonin reuptake inhibitors are at particular risk, and indeed care must be taken with a multiplicity of drugs with similar properties which are frequently used in anaesthesia and intensive care. Management of severe cases is by immediate paralysis accompanied by sedation and ventilation. This rapidly cuts off excess heat production and enables the body to restore thermal equilibrium. Milder cases can be managed with expectant observation alone.

\section{Hepatic and metabolic complications}

MDMA is a significant cause of drug-induced liver failure, accounting for up to $20 \%$ of all liver failure in patients under 25 years of age, possibly depending on local factors [31]. There are two distinct forms, one associated with hyper- pyrexia and the other occurring in isolation. The former is characterised by centrilobular necrosis and microvascular steatosis (as in heatstroke), whereas the latter is most often an acute cholestatic hepatitis with eosinophils and histiocytes probably indicating a hypersensitivity reaction [32,33]. A range of severity in both of these forms is noted clinically. The presentation is that of acute hepatitis, sometimes progressing to encephalopathy. Management is supportive. The promotion of abstinence in these patients is important as recurrence may occur on re-exposure to the drug.

Non-traumatic rhabdomyolysis is a complication common to many illicit substances. Two main mechanisms are usually responsible. The first is pressure necrosis of muscle in unconscious patients, sometimes complicated by compartment syndromes. The second is excessive muscle contraction leading to diffuse tissue disruption and consequent myoglobin release. These effects are aggravated by a variety of other derangements common in these patients, particularly hyperthermia and hypokalaemia. Either of these mechanisms may be further complicated by traumatic rhabdomyolysis, which is also common due to the effects of the substances taken, since they may cause aggression, impaired judgement, risk-taking behaviour, and impaired coordination.

There is frequently muscle swelling and tenderness but there may be no signs or symptoms. Even at an early stage, large amounts of haemoglobin and myoglobin can be found in the urine. Ultrasonagraphy can be of assistance in revealing hyperechoic regions of pressure necrosis in the asymptomatic patient. The diagnostic biochemical abnormality is a tenfold rise in CK, although aspartate transferase, alanine transferase, and lactate dehydrogenase are usually also raised. Acute renal failure is the usual sequel. Hyperkalaemia and hypocalcaemia can also occur.

Management consists of close monitoring of fluid and electrolyte status, with fluid replacement to produce an adequate urine output. Alkalinisation of urine is recommended to reduce the risk of myoglobinuric renal failure but may delay excretion of amphetamines. Biochemical abnormalities should 
be closely monitored and managed appropriately. Caution should be taken with calcium replacement as rebound hypercalcaemia may occur. Hyponatraemia, an important endocrine and metabolic complication of MDMA use, is described above in the section on neurological complications.

\section{Polysubstance abuse, clinical diagnosis, and the place of urine testing}

It is important for the clinician to be aware of the common toxidromes associated with illicit substance misuse as these can lead to a rapid clinical diagnosis (Table 2). In some cases, the diagnosis may be unclear. Since many drug complications may be difficult to distinguish from other medical conditions and since polysubstance use is common, it is often helpful to have the result of a rapid near-patient urine test to confirm clinical suspicion and guide management decisions. However, these tests only confirm the presence of a substance in urine, indicating consumption of the drug during the previous 24 to 72 hours, but do not give any indication of blood levels or of the relationship of the drug to the clinical effects observed. If the patient's mental state appears disturbed, consent for the test can be assumed. Interaction with alcohol must also be considered, especially in cases of cocaine abuse. Alcohol causes hepatic metabolism of cocaine to an ethyl homologue cocaethylene that has a plasma half-life three to five times longer than that (30 to 60 minutes) of cocaine [1]. Despite being a central nervous system depressant, alcohol is taken with cocaine to increase the desired effects of the latter, but it also increases cocaine's potential for toxicity. The risk of immediate death is 18 to 25 times greater for cocaine coingested with alcohol than for cocaine alone [34].

\section{Conclusion}

Because drug use is widespread and increasing, every medical practitioner needs to have a working understanding of the basic pharmacology and acute medical implications of illicit drugs. Emergencies may occur in an expected situation, such as at a club or party, but sometimes the patient is unable to give a coherent history and needs to be diagnosed from physical signs and clinical suspicion. Apart from management of the medical emergency, there is also an opportunity for the use of brief interventions in order to prevent further drug use by the patient; use of this 'teachable moment' has been shown to be effective in other situations. We hope that this short review will help to inform those who may encounter these complications in the course of their work.

\section{Competing interests}

The authors declare that they have no competing interests.

\section{References}

1. Tashkin DP: Airway effects of marijuana, cocaine, and other inhaled illicit agents. Curr Opin Pulm Med 2001, 7:43-61.

2. van der Klooster JM, Grootendorst AF: Severe bullous emphysema associated with cocaine smoking. Thorax 2001, 56:982983.
3. Johnson MK, Smith RP, Morrison D, Laszlo G, White RJ: Large lung bullae in marijuana smokers. Thorax 2000, 55:340-342.

4. Schmidt RA, Glenny RW, Godwin JD, Hampson NB, Cantino ME, Reichenbach DD: Panlobular emphysema in young intravenous Ritalin abusers. Am Rev Respir Dis 1991, 143:649-656.

5. Haim DY, Lippmann ML, Goldberg SK, Walkenstein MD: The pulmonary complications of crack cocaine. A comprehensive review. Chest 1995, 107:233-240.

6. Forrester JM, Steele AW, Waldron JA, Parsons PE: Crack lung: an acute pulmonary syndrome with a spectrum of clinical and histopathologic findings. Am Rev Respir Dis 1990, 142:462467.

7. Krantz AJ, Hershow RC, Prachand N, Hayden DM, Franklin C Hryhorczuk DO: Heroin insufflation as a trigger for patients with life-threatening asthma. Chest 2003, 123:510-517.

8. Qureshi Al, Suri MF, Guterman LR, Hopkins LN: Cocaine use and the likelihood of nonfatal myocardial infarction and stroke: data from the Third National Health and Nutrition Examination Survey. Circulation 2001, 103:502-506.

9. Lange RA, Cigarroa RG, Yancy CW Jr., Willard JE, Popma JJ, Sills MN, McBride W, Kim AS, Hillis LD: Cocaine-induced coronaryartery vasoconstriction. $N$ Engl J Med 1989, 321:1557-1562.

10. Moliterno DJ, Willard JE, Lange RA, Negus BH, Boehrer JD, Glamann DB, Landau C, Rossen JD, Winniford MD, Hillis LD: Coronary-artery vasoconstriction induced by cocaine, cigarette smoking, or both. N Engl J Med 1994, 330:454-459.

11. Hollander JE: The management of cocaine-associated myocardial ischemia. N Engl J Med 1995, 333:1267-1272.

12. McLaurin M, Apple FS, Henry TD, Sharkey SW: Cardiac troponin $\mathrm{I}$ and $\mathrm{T}$ concentrations in patients with cocaine-associated chest pain. Ann Clin Biochem 1996, 33:183-186.

13. Baumann BM, Perrone J, Hornig SE, Shofer FS, Hollander JE: Randomized, double-blind, placebo-controlled trial of diazepam, nitroglycerin, or both for treatment of patients with potential cocaine-associated acute coronary syndromes. Acad Emerg Med 2000, 7:878-885.

14. Honderick T, Williams D, Seaberg D, Wears R: A prospective, randomized, controlled trial of benzodiazepines and nitroglycerine or nitroglycerine alone in the treatment of cocaine-associated acute coronary syndromes. Am J Emerg Med 2003, 21: 39-42.

15. Lange RA, Cigarroa RG, Wells PJ, Kremers MS, Hills LD: Influence of anterograde flow in the infarct artery on the incidence of late potentials after acute myocardial infarction. $A m \mathrm{~J}$ Cardiol 1990, 65:554-558.

16. Boehrer JD, Moliterno DJ, Willard JE, Hillis LD, Lange RA: Influence of labetalol on cocaine-induced coronary vasoconstriction in humans. Am J Med 1993, 94:608-610.

17. Ehret GB, Voide C, Gex-Fabry M, Chabert J, Shah D, Broers B, Piguet V, Musset T, Gaspoz JM, Perrier A, et al.: Drug-induced long QT syndrome in injection drug users receiving methadone: high frequency in hospitalized patients and risk factors. Arch Intern Med 2006, 166:1280-1287.

18. Hartung TK, Schofield E, Short AI, Parr MJ, Henry JA: Hyponatraemic states following 3,4-methylenedioxymethamphetamine (MDMA, 'ecstasy') ingestion. QJM 2002, 95:431-437.

19. Westover AN, McBride S, Haley RW: Stroke in young adults who abuse amphetamines or cocaine: a population-based study of hospitalized patients. Arch Gen Psychiatry 2007, 64: 495-502.

20. Nanda A, Vannemreddy P, Willis B, Kelley R: Stroke in the young: relationship of active cocaine use with stroke mechanism and outcome. Acta Neurochir Supp/ 2006, 96:91-96.

21. Howington JU, Kutz SC, Wilding GE, Awasthi D: Cocaine use as a predictor of outcome in aneurysmal subarachnoid hemorrhage. J Neurosurg 2003, 99:271-275.

22. Hagel J, Andrews G, Vertinsky T, Heran MK, Keogh C: 'Chasing the dragon' - imaging of heroin inhalation leukoencephalopathy. Can Assoc Radiol J 2005, 56:199-203.

23. Ruttenber AJ, Lawler-Heavner J, Yin M, Wetli CV, Hearn WL, Mash DC: Fatal excited delirium following cocaine use: epidemiologic findings provide new evidence for mechanisms of cocaine toxicity. J Forensic Sci 1997, 42:25-31.

24. Marzuk PM, Tardiff K, Leon AC, Hirsch CS, Portera L, lqbal MI, Nock MK, Hartwell N: Ambient temperature and mortality from unintentional cocaine overdose. JAMA 1998, 279:1795-1800.

25. Henry JA, Jeffreys KJ, Dawling S: Toxicity and deaths from 3,4- 
methylenedioxymethamphetamine ('ecstasy'). Lancet 1992, 340:384-387.

26. Schifano F, Oyefeso A, Webb L, Pollard M, Corkery J, Ghodse $\mathrm{AH}$ : Review of deaths related to taking ecstasy, England and Wales, 1997-2000. BMJ 2003, 326:80-81.

27. Green AR, O'Shea E, Saadat KS, Elliott JM, Colado MI: Studies on the effect of MDMA ('ecstasy') on the body temperature of rats housed at different ambient room temperatures. $\mathrm{Br} J$ Pharmacol 2005, 146:306-312.

28. Mallick A, Bodenham AR: MDMA induced hyperthermia: a survivor with an initial body temperature of $\mathbf{4 2 . 9}$ degrees $C$. J Accid Emerg Med 1997, 14:336-338.

29. Bouchama A, Cafege A, Devol EB, Labdi O, el-Assil K, Seraj M: Ineffectiveness of dantrolene sodium in the treatment of heatstroke. Crit Care Med 1991, 19:176-180.

30. Hall AP, Henry JA: Acute toxic effects of 'Ecstasy' (MDMA) and related compounds: overview of pathophysiology and clinical management. $\mathrm{Br} J$ Anaesth 2006, 96:678-685.

31. Andreu V, Mas A, Bruguera M, Salmeron JM, Moreno V, Nogue S, Rodes J: Ecstasy: a common cause of severe acute hepatotoxicity. J Hepatol 1998, 29:394-397.

32. Ellis AJ, Wendon JA, Portmann B, Williams R: Acute liver damage and ecstasy ingestion. Gut 1996, 38:454-458.

33. Fidler H, Dhillon A, Gertner D, Burroughs A: Chronic ecstasy (3,4-methylenedioxymetamphetamine) abuse: a recurrent and unpredictable cause of severe acute hepatitis. J Hepatol 1996, 25:563-566.

34. Andrews P: Cocaethylene toxicity. J Addict Dis 1997, 16:75-84.

35. Mokhlesi B, Garimella PS, Joffe A, Velho V: Street drug abuse leading to critical illness. Intensive Care Med 2004, 30:15261536. 